\title{
Effect of Physical Exercise and Gender on Information Processing and Choice Reaction Time of University Students
}

\author{
Said Lotfi ${ }^{1}$, Imane Elmoutaraji ${ }^{2, *}$, Mohammed Talbi ${ }^{2}$ \\ ${ }^{1}$ Laboratory of Education and Training Sciences, University Hassan II Casablanca, Morocco \\ ${ }^{2}$ Laboratory of Analytical Chemistry and Physico-chemistry of Materials, University Hassan II Casablanca, Morocco
}

Received October 27, 2019; Revised December 16, 2019; Accepted December 25, 2019

Copyright $\odot 2020$ by authors, all rights reserved. Authors agree that this article remains permanently open access under the terms of the Creative Commons Attribution License 4.0 International License

\begin{abstract}
The study aimed to examine the impact of a team sport match on the cognitive coding-decoding system and the psychomotor reaction time on university students. Twenty-one healthy university learners (average age $=21.5 \pm .3$ years) were administered the WAIS-IV scales and Leed Test psychomotors before and after a single bout of exercise. The exercise treatments consisted of a 5-min warm-up, a 5-min cooldown, and handball game for $20 \mathrm{~min}$. The means were compared by ANOVA at the .05 significance level. The results revealed that exercise treatment resulted in significantly enhanced performance across Speed of information processing $(\mathrm{p}<.000)$, visual perception $(\mathrm{p}<.005)$ and choice reaction time $(\mathrm{p}<.040)$. Furthermore, under the effect of gender, the performances of males in total reaction time were significantly $(\mathrm{p}<.05)$ higher than females at rest and after exercise. But no significant difference was noted in the speed of treatment information and visual perception time. It is suggested that physical activity can be used as a means of stimulating cognitive skills and student development in university training programs in order to optimize certain cognitive functions and improve learning.
\end{abstract}

Keywords Information Processing, Visual Perception, Reaction Time, Physical Exercise, Gender

\section{Introduction}

Current research increasingly demonstrates the different effects of physical activity on mental functions and neuropsychological skills following a single bout of exercise. [1-3]. These induce both transient and permanent changes in cognitive performance [4]. Several studies have also shown positive effects perceptual skills
[5] on types of memory [5, 6], simple and choice reaction time [7] ability to solve mathematical problems [8] and concentration [9-11].

A large number of studies have focused on the relationship between exercise duration and cognitive function. Specifically, the results of an experimental study [12] which prescribes exercise to enhance cognition in healthy younger adults. This study indicates that acute aerobic exercise for $20 \mathrm{~min}$ at a moderate intensity produced significantly better cognitive performance, as assessed by shorter response time and higher accuracy and this improvement was not observed when exercising for more or less duration.

Neurophysiological parameters are also evaluated in several experimental studies. Indeed, aerobic training increases the level of neurotrophic factors derived from the brain [13] synaptic development and cerebral plasticity [14] and the development of new neurons [15].It has also demonstrated that regular physical activity slows the cognitive decline associated with aging [15-18] as well as the decline in sensorimotor functions [19].

Gender differences have been shown to vary across cognitive domains [20], with some evidence of gender differences in brain activity during cognitive tasks [21].However, the effect of gender is not well understood for central executive processes [22], inhibitory control [23] or treatment speed [24]. Although some studies have reported a slight male advantage in speed for reaction time simple and/or choice $[24,25]$.Others have not found this effect [26].

\section{Objectives}

The aim of this study is to examine the impact of a team sport match on the cognitive coding-decoding system and 
the psychomotor reaction time. In addition, the study was designed to consider the effect of gender on cognitive tasks namely visual perception, information processing and motor response. We hypothesized that team sport match enhance performance on cognitive coding-decoding tasks and the psychomotor reaction time.

\section{Methods}

\subsection{Research Type}

This research was conducted to assess the effect of physical activity and gender on the cognitive performance of the coding-decoding system and the psychomotor reaction of university students in order to optimize their learning. This study was conducted following the pre-post test model of quantitative research methods. Thus, the measurements were established before and after the experiment in order to be able to compare and interpret the results obtained

\subsection{Research Design}

Cognitive and psychomotor tests are performed collectively in the laboratory premises at full rest and after 20 minutes of recovery from the physical activity session. The tests are administered in the morning from $10 \mathrm{am}$ to $12 \mathrm{am}$.

\subsection{Subjects}

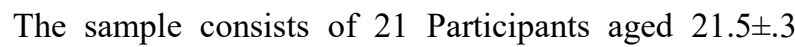
years (10 male, 11 females). Volunteers students, all follow a three years training in Physical education and Sports at Hassan II University, Casablanca. They are all in physical health, non-smokers and regularly practice their sports during and outside training.

\subsection{Mesures}

\subsubsection{Digit Symbol Substitution Test}

The Digit Symbol Substitution Test (DSST) is a subscale of Wechsler Adult Intelligence Scale [27]. It measures the information processing speed [28], short term memory, visual discrimination, visual perception, visual-motor coordination, visual scanning and attention, cognitive flexibility (reflecting the central integration capability of the central nervous system.

The subjects receive a sheet of paper with numerical references corresponding to different symbols each time. The subject must write, in boxes, the symbol corresponding to each digit from $1-9$ presented randomly, as quickly as possible. The subject is also asked to write below each of the digits the corresponding symbol under good working conditions. The score will be recorded as the number of correct symbols drawn in 10 min and the number of errors made. The DSST test is very sensitive to psychostimulant factors.

\subsubsection{Psychomotor Reaction Time Tests}

In order to examine the reaction speed of choice, we used the Leeds Psychomotor Tester which is an is an instrument that measures several psychomotor parameters such as the critical flicker fusion threshold and choice reaction time (CRT) [29, 30].In our study we used this test in order to assesses the integrity of the sensorimotor system and is an accurate measure of psychomotor performance [30].

Participants were seated on a chair in front of a table on which the instrument of Leeds psychomotor tester was positioned. An example was presented to the participants, prior to the test trials for the pattern recall test. The task for the participants was to respond to a bright red color light that appears one of 6 led lights randomly by pressing the button where the red light shown. The buttons were equidistant from the resting position of the finger. Thus for each participant we measured recognition reaction time (RRT) that occurs from the stimulus onset to the beginning of motor action, as well as the time of motor reaction time (MRT) that represents the time from onset of motor action to the end of performance. The total choice reaction time (TRT) corresponds to the sum of these two times (TRT $=$ RRT + MRT). The reaction time recorded was the mean of five stimulus responses.

\subsubsection{Physical Exercise}

The participant had to perform a ten minutes standardized warm-up first. This contained five minutes of moderate jogging, followed by three minutes of handball specific movements. The warm-up was concluded with two minutes of stretching. Afterward, the students were divided randomly by sex into two teams, to play a 20-minute of a single match session in Handball which is a physical exercise that involves both the aerobic and anaerobic component of lactic energy. This exercise session was practiced in the morning at 09:30 am in a cool and not very humid climate.

\subsection{Statistical Analysis}

The results are presented as mean and standard deviation. The comparison of means is performed by ANOVA II evaluating the exercise effect, the gender effect, and the interaction effect exercise $\mathrm{x}$ gender. The significance probability with critical level set at .05. Data were expressed as mean \pm standard deviation.

\section{Results}

Data from psychomotor and cognitive test results are presented in Table 1. 
Table 1. Variation in cognitive coding-decoding performance and psychomotor reaction time

\begin{tabular}{|c|c|c|c|c|c|c|c|c|}
\hline & & \multicolumn{2}{|c|}{ At rest } & \multicolumn{2}{|c|}{ After exercise } & \multicolumn{3}{|c|}{ ANOVA II $(p)$} \\
\hline Parameters $(n=21)$ & & Averages & $\pm \mathrm{Sd}$ & Averages & $\pm \mathrm{Sd}$ & $\begin{array}{c}\text { Exercise } \\
\text { effect }\end{array}$ & Gender effect & $\begin{array}{c}\text { Interaction } \\
\text { effect }\end{array}$ \\
\hline \multirow{3}{*}{ Score DSST } & Females & 319.27 & 49.47 & 363.94 & 51.57 & \multirow{3}{*}{.000} & \multirow{3}{*}{ NS } & \multirow{3}{*}{ NS } \\
\hline & Males & 345.00 & 37.18 & 392.70 & 53.75 & & & \\
\hline & Total & 331.52 & 44.93 & 377.63 & 53.35 & & & \\
\hline \multirow{3}{*}{ Number of errors } & Females & 1.64 & 2.34 & 2.97 & 2.79 & \multirow{3}{*}{ NS } & \multirow{3}{*}{ NS } & \multirow{3}{*}{ NS } \\
\hline & Males & 2.50 & 2.37 & 2.40 & 1.26 & & & \\
\hline & Total & 2.05 & 2.33 & 2.70 & 2.17 & & & \\
\hline \multirow{3}{*}{ Visuel perception time (CRT1) } & Females & 377.91 & 108.33 & 310.82 & 68.33 & \multirow{3}{*}{.005} & \multirow{3}{*}{ NS } & \multirow{3}{*}{ NS } \\
\hline & Males & 338.20 & 59.04 & 299.90 & 44.90 & & & \\
\hline & Total & 359.00 & 88.60 & 305.62 & 57.21 & & & \\
\hline \multirow{3}{*}{ Total reaction time (CRT2) } & Females & 569.91 & 79.76 & 512.73 & 75.89 & \multirow{3}{*}{.040} & \multirow{3}{*}{.001} & \multirow{3}{*}{ NS } \\
\hline & Males & 471.20 & 62.69 & 419.10 & 117.18 & & & \\
\hline & Total & 522.90 & 86.61 & 468.14 & 106.56 & & & \\
\hline \multirow{3}{*}{$\begin{array}{l}\text { Motor response time } \\
\quad(\text { CRT2-CRT1) }\end{array}$} & Females & 192.00 & 46.15 & 201.91 & 59.17 & \multirow{3}{*}{ NS } & \multirow{3}{*}{.000} & \multirow{3}{*}{ NS } \\
\hline & Males & 133.00 & 21.60 & 141.00 & 42.54 & & & \\
\hline & Total & 163.90 & 46.76 & 172.90 & 59.47 & & & \\
\hline
\end{tabular}

Note: Sd: Standard deviation, NS : non significative CRT : choice reaction time

\subsection{Speed of Information Processing}

The cognitive code-decoding test scores show a highly significant increase $(\mathrm{p}<.000)$ of $13.90 \%$ under the effect of exercise. The scores recorded by males exceed those of females, at rest $(+8.05 \%)$ and after physical exercise $(+7.90 \%)$. However, these variations remain insignificant. The means of the errors made in the code-decoding test is also not significant under the effect of the exercise.

\subsection{Time of Visual Perception}

The results analyzed by ANOVA II on changes in Visual perception time show an overall significant decrease $(p<.005)$ of $14.86 \%$ after exercise. While, the gender effect and its interaction (exercise effect $\mathrm{x}$ gender effect) with exercise remains insignificant.

\subsection{Motor Response Time}

The results show that following physical exercise the motor response time increases slightly by $5.49 \%$ in a non-significant way. However, in comparison between males and females the analysis of ANOVA II shows a highly significant effect $(p<.000)$ of gender on the speed of motor reaction. In fact, the motor response time in females is $44.36 \%$ longer at rest and $43.19 \%$ longer after physical exercise.

\subsection{Speed of Choice Reaction Time}

The scores on the total reaction time decreased significantly $(p<.040)$ by $11.69 \%$ under the effect of physical exercise. We also report a highly significant effect $(\mathrm{p}<.001)$ of gender on Total reaction time scores. The females' averages are $11.01 \%$ and $11.70 \%$ higher than the males respectively at rest and after exercise.

\section{Discussion}

The objective of this study is to evaluate the impact of handball game on the performance of cognitive and psychomotor information processing in university athletes. The tests administered to our sample mobilized, on the one hand, the repetitive cognitive coding/decoding system, which is an indicator of information processing speed, and on the other hand the psychomotor reaction speed (choice reaction time) by exploring the three components: perceptive, motor and sensorimotor factor.

The results obtained show a significant increase of 9.5 to $15 \%$ in our subjects' cognitive coding-decoding speed and psychomotor reaction speed after a collective activity match 20 min even after 20 min of recovery. This finding demonstrates the positive effect of collective play on the activation of cognitive processes at the visual perception level, and rapid motor decision-making. Previous studies have shown that physical activity acts as a cognitive stimulant [31-33], electrophysiological [34], and neurophysiological[35] in different subject profiles.

In our work, we noted a significant improvement in the choice reaction time under the effect of the collective exercise. However, Kashihara and Nakahara [36] also found that vigorous exercise improved response time of choice, but only during the first 8 minutes after exercise. Other work by Collardeau et al [37] found that exercise 
improved runner reaction time during exercise, and not after.

However, compared to our results, McMorris et al. [38] found no effect of exercise on reaction time in a football skill test, and [39]Lemmink and Visscher noted that reaction time and error rate of football players were not affected.

Moreover, certain works [40] (Tomporowskim have shown effects differentiated according to the cognitive demand linked to the task, which means that each physical exercise requires a cerebral part and precise mental faculties according to the intensity, nature and variety of physical exercise.

The results obtained during this study show significantly that men have faster reaction time than women. Bellis [41] reported that the average time to press a key in response to a light was $220 \mathrm{msec}$ for men and 260 msec for women. This finding is also observed in several studies [25], [42, 43] which also found that the practice does not reduce these female disadvantages.

This difference between men and women is due, according to [44] Botwinick and Thompson, to the time lag between the presentation of the stimulus and the onset of muscle contraction, not at the time of the muscular contraction was. However, in our findings we found no significant change at the Visuel perception time level. It was at the motor response time level that we raised a highly significant effect of sex with a male advantage. This can be explained by the words of Adam et al. [45] who reported that men use a more complex strategy than women or by speed-precision composition. Barral and Debu [46] found that while men were faster at targeting than women, women were more specific.

\section{Conclusions}

The present study showed that physical exercise has a favorable impact on certain cognitive functions especially the performance of decoding-coding through the cognitive processing speed of information. There was also a decrease in the time of the psychomotor reaction to the choices after 20 minutes of recovery from the collective exercise session. Our findings also reported an effect of gender with a significant male advantage on the motor reaction speed and choice reaction time. Whereas, the interaction gender exercise has no effect either on the performance of the cognitive coding-decoding or on the reaction time to the choice. These results underline the beneficial contribution of physical exercise in improving the cognitive functioning of coding-decoding and the time of the reaction to choices, which is exploited at the level of the learning process of individuals. Thus, according to this study, the acute aerobic exercise acts like an arousing that facilitates the increase of performance of sensory and motor prosses of information processing. In addition, this evidence leads to the exploitation of physical activity as a means of stimulating cognitive skills and students' fulfillment in school and university training programs.

Other similar studies should therefore be conducted with a larger number of participants with different levels of training, using a battery of tasks to test the differences in cognitive skills between gender and level of sport expertise in order to elucidate precisely the mechanisms which underlie the effects of acute exercise on cognitive profil

\section{REFERENCES}

[1] Y. K. Chang, J. D. Labban, J. I. Gapin, and J. L. Etnier, "The effects of acute exercise on cognitive performance: a meta-analysis," Brain Res., vol. 1453, pp. 87-101, May 2012.

[2] K. Lambourne and P. Tomporowski, "The effect of exercise-induced arousal on cognitive task performance: A meta-regression analysis," Brain Research, vol. 1341, pp. 12-24, Jun. 2010.

[3] L. Verburgh, M. Königs, E. J. A. Scherder, and J. Oosterlaan, "Physical exercise and executive functions in preadolescent children, adolescents and young adults: a meta-analysis," Br J Sports Med, vol. 48, no. 12, pp. 973-979, Jun. 2014.

[4] M. Audiffren, N. André, and C. Albinet, "Effets positifs de l'exercice physique chronique sur les fonctions cognitives des seniors: bilan et perspectives," Revue de neuropsychologie, vol. 3, p. 207, Jan. 2011.

[5] S. Lotfi and S. Karyouh, "Effect of Physical Exercise on Neurocognitive Performances in University Students," vol. 3, no. 6, p. 7, 2016.

[6] C. Pesce, C. Crova, L. Cereatti, R. Casella, and M. Bellucci, "Physical activity and mental performance in preadolescents: Effects of acute exercise on free-recall memory," Mental Health and Physical Activity, vol. 2, no. 1, pp. 16-22, Jun. 2009.

[7] D. Ellemberg and M. St-Louis-Deschênes, "The effect of acute physical exercise on cognitive function during development," Psychology of Sport and Exercise, vol. 11, no. 2, pp. 122-126, Mar. 2010.

[8] D. McNAUGHTEN and C. Gabbard, "Physical exertion and immediate mental performance of sixth-grade children," Perceptual and motor skills, vol. 77, pp. 1155-9, Jan. 1994.

[9] S. Raviv and M. Low, "Influence of physical activity on concentration among junior high-school students," Percept Mot Skills, vol. 70, no. 1, pp. 67-74, Feb. 1990.

[10] M. C. Caterino and E. D. Polak, "Effects of two types of activity on the performance of second-, third-, and fourth-grade students on a test of concentration," Percept Mot Skills, vol. 89, no. 1, pp. 245-248, Aug. 1999.

[11] H. Budde, C. Voelcker-Rehage, S. Pietrabyk-Kendziorra, P. 
Ribeiro, and G. Tidow, "Acute coordinative exercise improves attentional performance in adolescents," Neuroscience letters, vol. 441, pp. 219-23, Sep. 2008.

[12] Y.-K. Chang et al., "Dose-response relation between exercise duration and cognition.," Medicine and science in sports and exercise, vol. 47, no. 1, pp. 159-165, 2015.

[13] S. A. Neeper, F. Gómez-Pinilla, J. Choi, and C. Cotman, "Exercise and brain neurotrophins," Nature, vol. 373, no. 6510, p. 109, Jan. 1995.

[14] B. Lu and A. Chow, "Neurotrophins and hippocampal synaptic transmission and plasticity," J. Neurosci. Res., vol. 58, no. 1, pp. 76-87, Oct. 1999.

[15] H. van Praag, B. R. Christie, T. J. Sejnowski, and F. H. Gage, "Running enhances neurogenesis, learning, and long-term potentiation in mice," Proc. Natl. Acad. Sci. U.S.A., vol. 96, no. 23, pp. 13427-13431, Nov. 1999.

[16] M. Audiffren, P. Tomporowski, and J. Zagrodnik, "Acute aerobic exercise and information processing: Modulation of executive control in a Random Number Generation task," Acta psychologica, vol. 132, pp. 85-95, Aug. 2009.

[17] R. Cardoso Cassilhas et al., "The Impact of Resistance Exercise on the Cognitive Function of the Elderly," Medicine and science in sports and exercise, vol. 39, pp. 1401-7, Sep. 2007

[18] S. J. Colcombe et al., "Cardiovascular fitness, cortical plasticity, and aging," Proc. Natl. Acad. Sci. U.S.A., vol. 101, no. 9, pp. 3316-3321, Mar. 2004.

[19] K. Tanaka, A. C. de Quadros, R. F. Santos, F. Stella, L. T. B. Gobbi, and S. Gobbi, "Benefits of physical exercise on executive functions in older people with Parkinson's disease," Brain Cogn, vol. 69, no. 2, pp. 435-441, Mar. 2009.

[20] T. Hedden and J. Gabrieli, Hedden T, Gabrieli JD. Insights into the ageing mind: a view from cognitive neuroscience. Nat Rev Neurosci 5: 87-96, vol. 5. 2004.

[21] D. Gerstorf, A. Herlitz, and J. Smith, "Stability of Sex Differences in Cognition in Advanced Old Age: The Role of Education and Attrition," The journals of gerontology. Series B, Psychological sciences and social sciences, vol. 61, pp. P245-9, Aug. 2006.

[22] E. C. Bell, M. C. Willson, A. H. Wilman, S. Dave, and P. H. Silverstone, "Males and females differ in brain activation during cognitive tasks," NeuroImage, vol. 30, no. 2, pp. 529-538, Apr. 2006.

[23] B. S. McEwen, "The neurobiology of stress: from serendipity to clinical relevance," Brain Res., vol. 886, no. 1-2, pp. 172-189, Dec. 2000

[24] C. Macleod, "Half a Century of Research on the Stroop Effect - an Integrative Review," Psychol. Bull., vol. 109, no. 2, pp. 163-203, Mar. 1991.

[25] I. J. Deary and G. Der, "Reaction Time, Age, and Cognitive Ability: Longitudinal Findings from Age 16 to 63 Years in Representative Population Samples," Aging, Neuropsychology, and Cognition, vol. 12, no. 2, pp. 187-215, Jun. 2005.

[26] G. Der and I. J Deary, "Age and sex differences in reaction time in adulthood: Results from the United Kingdom Health and Lifestyle Survey," Psychology and aging, vol. 21, pp. 62-73, Apr. 2006.

[27] E. J. Meinz and T. A. Salthouse, "The effects of age and experience on memory for visually presented music," J Gerontol B Psychol Sci Soc Sci, vol. 53, no. 1, pp. P60-69, Jan. 1998

[28] "WAIS-IV - Échelle d'intelligence de Wechsler pour adultes - 4ème édition," Pearson Clinical \& Talent Assessment. [Online].

Available:https://www.pearsonclinical.fr/wais-iv-nouvelle -version-de-lechelle-dintelligence-de-wechsler-pour-adulte s-quatrieme-edition. [Accessed: 13-May-2019].

[29] O. Spreen and E. Strauss, A compendium of neuropsychological tests: Administration, norms, and commentary, 2nd ed. New York, NY, US: Oxford University Press, 1998.

[30] I. Hindmarch, "Psychomotor function and psychoactive drugs.," Br J Clin Pharmacol, vol. 10, no. 3, pp. 189-209, Sep. 1980.

[31] I. Hindmarch, "Critical Flicker Fusion Frequency (CFF): The Effects of Psychotropic Compounds," Pharmacopsychiatry, vol. 15, pp. 44-48, Jan. 1982.

[32] C. Hertzog, A. F. Kramer, R. S. Wilson, and U. Lindenberger, "Enrichment Effects on Adult Cognitive Development: Can the Functional Capacity of Older Adults Be Preserved and Enhanced?," Psychol Sci Public Interest, vol. 9, no. 1, pp. 1-65, Oct. 2008.

[33] P. Ghisletta, J.-F. Bickel, and M. Lövdén, "Does Activity Engagement Protect Against Cognitive Decline in Old Age? Methodological and Analytical Considerations," The journals of gerontology. Series B, Psychological sciences and social sciences, vol. 61, pp. P253-61, Oct. 2006.

[34] T. A. Salthouse, D. E. Berish, and J. D. Miles, "The role of cognitive stimulation on the relations between age and cognitive functioning," Psychol Aging, vol. 17, no. 4, pp. 548-557, Dec. 2002.

[35] G. Csibra, E. Kushnerenko, and T. Grossmann, "Electrophysiological methods in studying infant cognitive development," in Handbook of developmental cognitive neuroscience, 2nd ed, Cambridge, MA, US: MIT Press, 2008, pp. 247-262.

[36] F. Chaouloff, G. A. Kennett, B. Serrurrier, D. Merino, and G. Curzon, "Amino acid analysis demonstrates that increased plasma free tryptophan causes the increase of brain tryptophan during exercise in the rat," J. Neurochem., vol. 46, no. 5, pp. 1647-1650, May 1986.

[37] K. Kashihara and Y. Nakahara, "Short-term effect of physical exercise at lactate threshold on choice reaction time," Perceptual and motor skills, vol. 100, pp. 275-91, May 2005.

[38] M. Collardeau, J. Brisswalter, and M. Audiffren, "Effects of a prolonged run on simple reaction time of well trained runners," Percept Mot Skills, vol. 93, no. 3, pp. 679-689, Dec. 2001.

[39] T. Mcmorris and J. Graydon, "The effect of incremental exercise on cognitive performance," International Journal 
of Sport Psychology, vol. 31, Jan. 2000.

[40] K. A. P. M. Lemmink and C. Visscher, "Effect of intermittent exercise on multiple-choice reaction times of soccer players," Percept Mot Skills, vol. 100, no. 1, pp. 85-95, Feb. 2005.

[41] P. D. Tomporowski, C. L. Davis, P. H. Miller, and J. A. Naglieri, "Exercise and Children's Intelligence, Cognition, and Academic Achievement," Educ Psychol Rev, vol. 20, no. 2, pp. 111-131, Jun. 2008.

[42] C. J. Bellis, "Reaction time and chronological age," Proceedings of the Society for Experimental Biology \& Medicine, vol. 30, pp. 801-803, 1933.

[43] A. Welford, "Relationships between reaction time and fatigue, stress, age and sex. Reaction times," pp, pp. 321-354, 1980.

[44] S. Dane and A. Erzurumluoglu, "Sex and handedness differences in eye-hand visual reaction times in handball players," The International journal of neuroscience, vol. 113, pp. 923-9, Aug. 2003.

[45] J. Botwinick and L. W. Thompson, "Components of reaction time in relation to age and sex," J Genet Psychol, vol. 108, no. 2d Half, pp. 175-183, Jun. 1966.

[46] "Gender differences in choice reaction time: evidence for differential strategies. - PubMed - NCBI." [Online]. Available:https://www.ncbi.nlm.nih.gov/pubmed/1002485 1. [Accessed: 13-May-2019].

[47] J. Barral and B. Debû, "Aiming in adults: sex and laterality effects," Laterality, vol. 9, no. 3, pp. 299-312, Jul. 2004. 